\title{
LA ALTERNA CASA DE LA LAGUNA: EXPEDIENTE DE JUSTICIA AMBIENTAL
}

\author{
POR \\ Áurea María Sotomayor-Miletti \\ University of Pittsburgh
}

En esta lectura ${ }^{1}$ de La casa de la laguna privilegio un suceso inicial de la trama: el ocultamiento de una fuente de agua, un presunto acto delictivo que no excluye el asesinato y que funda el progreso económico de la familia protagónica. En lugar de rastrear genealogías, gesto frecuente en la crítica sobre la obra de Rosario Ferré, discurro sobre la fuente del valor, en este caso preservada para consumo exclusivamente individual. Aquí se disputan los bienes de dominio público y los de dominio privado al interior mismo de la trama y de la casa, a la cual paradójicamente se llega atravesando un caño por el cual fluye la hibridez racial que puebla la novela. Leo el texto a la luz de las transformaciones que han signado las zonas aledañas a la ciudad murada de San Juan, las políticas económicas desarrollistas de un estado periférico, así como las relaciones entre sus habitantes.

Los terrenos bajos son lugares de emplazamiento de las clases más pobres, hasta que en virtud del tiempo se secan, constituyendo éstos una ganancia para quien las ocupa. Es lo que ocurre con algunas de estas zonas bajas sin titularidad que adquieren valor con el transcurso del tiempo y son codiciadas por las empresas de construcción y el turismo. Se intenta entonces desplazar al ocupante, quien de no recurrir a la figura de la usucapión, ${ }^{2}$ es privado de las tierras en que ha vivido por décadas. Intento aproximar aquí el discurso jurídico al discurso literario subrayando las disputas recientes relacionadas con los reclamos realizados sobre los bienes y espacios públicos desde la perspectiva de la justicia ambiental y la planificación urbana en Puerto Rico. ${ }^{3}$ La casa de la laguna emplaza en una zona límite entre Miramar, Condado y Cangrejos, por lo que una reflexión sobre ese espacio en que se construye y donde confluye la racialización, la marginación y el ilícito evoca controversias recientes relacionadas con los desarrollos urbanos y los

Presentado en LASA, San Francisco, mayo 2012.

2 Es el derecho que tiene un ocupante de un inmueble por varias décadas (el lapso de tiempo depende de cada jurisdicción), quien habiendo ocupado la propiedad de buena fe sin nadie que se la dispute, tiene derecho a inscribir su título y convertirse en dueño erga omnes.

3 Véase Fontánez Torres. Hay una versión publicada en el volumen Derecho y Propiedad. 
regímenes de dominio público, en lo que se ha denominado el Caso "Paseo Caribe" y los regímenes de propiedad alterna y comunitaria en el Caño Martín Peña, antiguo arrabal de la ciudad de San Juan.

La casa de la laguna ha sido interpretada frecuentemente en el marco de las narrativas relativas a las gramáticas del árbol genealógico familiar, cuyo modelo fue la gran saga latinoamericana de Cien años de soledad. La autora emplaza la acción de su novela en un espacio de creciente modernización ubicado en la zona capitalina, aledaña al Viejo San Juan, por Miramar y Cangrejos, donde empiezan a asentarse tanto las clases acomodadas como las pobres a inicios del siglo XX. Se trata de una zona de desarrollo desigual y en ciernes, y la novela relata el devenir económico de la cabeza de familia y de su descendencia para cifrar el espacio en que emplazan y viven. El espacio habitado radica en un escenario único y en tránsito donde el desplazamiento entre la marisma, la laguna y el mar marca las relaciones familiares en un adentro que se desdobla en términos raciales y relaciones de clase. La casa emplaza en zona lacustre o terreno bajo y los cimientos lo atestiguan. El agua es el fundamento de todo y los cimientos de la casa allí radican: de frente se halla el Océano Atlántico y tras esa fachada, todo un escenario lacustre poblado de cangrejos evoca la población negra que habitó esta zona. ${ }^{4}$ Es decir, el emplazamiento físico de la casa, lo que un estudioso ha llamado el espacio percibido (el material donde se llevan a cabo prácticas sociales) (Lefebvre) permite un tráfico secreto de naturaleza racial, sexual, económica y política, que genera la posterior rebelión política del hijo. Esto aflora principalmente al finalizar la novela porque antes se narra el surgimiento del texto, así como del capital de los Buenaventura y su emblema, la casa en la laguna, sujeta a una modificación constante y paulatina por razón de las transformaciones que sobre ella va operando el capital y las modas arquitectónicas de la clase ascendente, desde el "Spanish Revival" hasta el Modernismo a lo Wright. ${ }^{5}$

Paralelo a la consolidación del capital en manos del patriarca como comerciante emprendedor y autosuficiente, se va puntualizando en la novela la historia política y económica de Puerto Rico. La pugna por ocupar el lugar de la ciudad más poderosa, si Ponce o San Juan, es parte del subtexto de esta novela donde se contraponen dos voces, una femenina y otra masculina, y se recuenta en gran medida la disputa existente a principios del siglo XX respecto a qué ciudad constituiría el centro económico de la isla. En la primera generación se trata de un típico comerciante cuyo escudo familiar representa a un león devorando un cerdo, emblema evidente de la violencia. En la segunda, se trata además de un historiador que esgrime contra su esposa, la escritora

4 Para una historia demográfica, urbanística y arquitectónica de la zona, consúltese el libro de Edwin Quiles Rodríguez.

5 Véase Vivoni-Farage y Álvarez Curbelo, San Juan siempre nuevo, arquitectura y modernización en el siglo XX. También Vivoni-Farage y Álvarez Curbelo, Hispanofilia. Arquitectura y vida en Puerto Rico, 1900-1950.

$111 \frac{\text { Revista Iberoamericana, Vol. LXXXII, Núms. 255-256, Abril-Septiembre 2016, } 619-635}{\text { ISSN 0034-9631 (Impreso) }}$ 
frustrada cuya novela leemos, el discurso de la verdad, pues la narradora insiste en enfatizar las divergencias existentes entre los discursos del historiador y el discurso de la ficción. ${ }^{6}$ Como el historiador pretende representar la verdad, reduce la ficción de su esposa a la mentira, puntualizando a lo largo de los manuscritos ocultos que él encuentra de ella en la casa, los momentos en que aquélla falta a la verdad para poder justificar el complemento de su discurso. Después de varios desencuentros en el matrimonio y la insistencia del esposo para que ella desista de escribir y destruya el texto, ésta lo entrega a una criada negra para que lo custodie, pero al morir ésta se desconoce el paradero del texto. El custodio último es el artista e hijo menor del matrimonio, quien lo deposita en una caja llamada por él "los juguetes de Elegguá". El secreto guardado por ella esta vez se opone al del patriarca y evoca la colección de cuentos, Papeles de Pandora, primera colección de cuentos de Rosario Ferré. Ese secreto atañe al enigma que funda a la familia, específicamente el lugar donde se situó el patriarca para enclavar su casa. Basta recordar "La muñeca menor", primer cuento de la colección, para referirnos a otra versión del mito fundador, esta vez la explotación ejercida por un miembro de la incipiente clase media, la de los médicos, sobre la clase hacendada. Ese enigma relacionado con un cierto entrampamiento, picardía o fraude es el que continúa custodiando el hijo del patriarca y el esposo de la protagonista, Quintín Mendizábal. Éste teme el desprestigio de su familia una vez se publique la novela que su esposa escribe, la cual, según él, atenta contra la honra familiar al sugerir que su padre asesinó al hombre que ocupaba las tierras donde se funda la casa. En una escena final en que se frustra un robo en que se contaba con la complicidad de Isabel Monfort, la narradora, Quintín descubre que su primer hijo, Manuel, que se ha radicalizado políticamente, desea incendiar la casa, y que su esposa y su hijo menor lo desprecian por razón de su autoritarismo. En ese momento se desata una vez más la agresividad que ha caracterizado al protagonista (Quintín) desde los inicios de la novela, y se da paso a una típica escena de violencia doméstica. La protagonista (Isabel), en una tensa retrospección, percibe la ruptura de la promesa que le hiciera su esposo: evitar la violencia. Quintín muere golpeado por una de las vigas de hierro de la casa cuando lucha con su hijo mayor, mientras la narradora y su hijo menor se alejan en el bote, contemplando la imagen de la casa que se incendia.

\section{EL ACTO VIOLENTO DE FUNDACIÓN}

Con relación al Estado, ya Nietzsche lo dijo en la Genealogía de la moral: surge de un "puro acto de violencia" (y no de un contrato), según el cual el Estado convalida el deseo de ejercer un "señorío", y lo ejerce "una horda cualquiera de rubios animales

Hayden White cuestiona la oposición falsa entre ambos discursos en su libro Tropics of Discourse. Essays in Cultural Criticism. 
de presa, una raza de conquistadores y de señores, que organizados para la guerra, y dotados de la fuerza de organizar, coloca sin escrúpulo alguno sus terribles zarpas sobre una población tal vez tremendamente superior en número, pero todavía informe, todavía errabunda" (98). Páginas antes Nietzsche discurre "que todo acontecer en el mundo orgánico es un subyugar, un enseñorearse, y que, a su vez, todo subyugar y enseñorearse es un reinterpretar, un reajustar, en el que por necesidad, el 'sentido' anterior y la 'finalidad' anterior tienen que quedar oscurecidos o incluso totalmente borrados" (88). Entonces, la historia o genealogía de una cosa responde a una voluntad de poder y se manifiesta como "la sucesión de procesos de avasallamiento más o menos profundos" que ocurren en la cosa (88). El énfasis de Nietzsche en la figura del propietario feroz y depredador, del que se apodera de algo y ejerce un señorío apartando la cosa de su finalidad previa, no debe pasar desapercibido como el acto de violencia originaria que también signa los avatares de la familia que describe esta novela, donde el orden de presentación prefiere enfocar primero el sitio, la tierra y el lugar codiciado y, después, el habitante que será desplazado posteriormente.

La cosa es la casa en La casa de la laguna, donde todo confluye en ese acto avasallador y violento que funda la progenie, posterior al cual se consolida la riqueza familiar. Sobre una fuente de agua y no una piedra se edifica una casa que representa los altibajos del poder económico del patriarca. Ésta se modifica al ritmo de un desarrollismo económico periferal de acuerdo al cual la diversidad de estilos arquitectónicos registran los cambios políticos e identitarios del país (Iglesia). En una época y en consonancia con la genealogía y el comercio clandestino a través de los buques españoles que todavía abastecen la isla poco después de la invasión norteamericana, se produce una casa estilo Spanish Revival, mientras que más tarde en el siglo la casa que funda la generación posterior corresponde al modernista prairie style de Frank Lloyd Wright (Gallart). La casa nunca deja de ser un espacio social dispuesto a metamorfosearse como emblema de ostentación social. Sólo así es productiva. Sus transformaciones arquitectónicas en la novela responden a un momento económico en que jurídicamente la mujer no es aún condueña, sino un objeto más dentro del escaparate del titular. De no conservar adecuadamente la casa, los cimientos los debilita el mangle, esa extensión rizomática donde se confunde el agua dulce con el agua salada, como ocurre al concluir la novela:

De los cuartos de atrás emanaba un desagradable olor a fango y había cangrejos por todas partes, hasta trepados a las vigas de hierro que sostenían la terraza de Pavel. Me pregunté cómo se habrían multiplicado tan rápidamente, $\mathrm{y}$ al punto comprendí lo sucedido. Los sirvientes se habían marchado, y eran ellos los que los cazaban para comérselos. [...] Golpeaban con sus palancas en el piso mientras avanzaban lentamente, como un remolino de sombras. (423)

$111 \frac{\text { Revista Iberoamericana, Vol. LXXXII, Núms. 255-256, Abril-Septiembre 2016, } 619-635}{\text { ISSN 0034-9631 (Impreso) }}$ 
El origen de la progenie es el asesinato, razón por la cual, a esa fundación violenta corresponde uno de los epígrafes, que evoca el pasaje inolvidable con que se inicia $L a$ vorágine: "Antes que me hubiera apasionado por mujer alguna, jugué mi corazón al azar, y me ganó la Violencia” (79). En esa genealogía fundante de la casa, el hecho de sangre es el enigma que sustenta el poder. Que dicho poder se consolide simbólicamente en una casa rígidamente estratificada verticalmente entre los niveles superiores y el sótano atañe al esquema bachelardiano en Poética del espacio, a la racialización del espacio urbano (Goldberg) y, predominantemente, a la lectura nietzscheana de que el Estado y el régimen de la propiedad tienen su origen en esa violencia que nos ubica en una trama genealógica que atañe al principio de la riqueza. El principio violento corresponde al silencio que guarda el patriarca fundador al morir de forma misteriosa el habitante del predio de terreno lagunar codiciado por él, lugar donde posteriormente él enclavará su casa. Ello contrasta con la escena final de la novela, cuando su descendiente, el nieto del hijo mayor convertido en un guerrillero de parodia, roba los objetos de arte de su propio padre e incendia la casa, a manera de cuestionamiento y demolición del "Estado". Justo en el momento en que se recupera el manuscrito (escondido en el sótano precisamente) que la narradora, esposa del hijo del patriarca, ha ido elaborando en secreto, se afina el otro modo de la rebelión, porque en este se relata la genealogía del capital y el poder desde una perspectiva feminista. La novela constituye el relato de esa subversión, de ese apartamiento de la línea patrimonial y violenta, a través de una escritura que desenmascara el acto de fundación y narra las peripecias comerciales del patriarca.

\section{EL LUGAR DEL INTERMEDIO}

En el año de 1995 se decidió en el Tribunal Supremo de Puerto Rico un caso relacionado con un ojo de agua emplazado en terreno privado. ${ }^{7}$ Mientras los vecinos carecían del beneficio del agua e intentaban entrar a la finca para extraerla, el dueño ostentaba las prerrogativas del titular interponiendo un interdicto para prohibir el paso y vedar el consumo de aquella. El tribunal decidió que el agua, independientemente de donde surja, es un bien de todos y para todos, un elemento fundamental de la vida. Citando a los tratadistas A. Reverte Navarro y E. Pérez Pérez (Legislación de Aguas), se señala:

La combinación de indispensabilidad, revesado mantenimiento y alta vulnerabilidad del agua requieren una estrategia de conservación, desarrollo y administración eficaz, comprensiva y preventiva; labor tan enorme y costosa que por lo general sólo el Estado puede llevarla a cabo. Ante tal realidad, la gran mayoría de los ordenamientos jurídicos

Ver Paoli Méndez v. Rodríguez et al, 138 DPR 449 (1995). 
modernos -incluso aquellos que cuentan con vastos abastos de agua- han optado por promover la intervención gubernamental aun a costa de intereses propietarios individuales. (Cit. en Paoli Méndez 458)

En La casa de la laguna, territorio movedizo entre tierra y agua, tenemos el relato opuesto, pues allí se narra el tránsito de manos de un custodio del agua para consumo de todos, por ser de dominio público, a uno que se la apropia para sí. En la novela se describen los límites de la propiedad en el estilo de las escrituras de compraventa. Se señala al principio y al final que, por un lado, la propiedad colinda con la Avenida Ponce de León y por el otro con la laguna (426) o el manglar, que en el imaginario caribeño e insular, corresponde a todo aquéllo que oculta un secreto. ${ }^{8}$ La colindancia posterior de la mansión corresponde a un entramado constituido por el Caño Martín Peña, que está unido por el Puente Dos Hermanos, la Laguna y Ensenada de Cangrejos, la laguna de San José y la Laguna Torrecillas (hoy bajo el Puente Teodoro Moscoso, que conduce al Aeropuerto Internacional, y desde donde se divisa la Sierra de Luquillo), que a su vez une a la Playa de Piñones. ${ }^{9}$ La referencia geográfica de tipo acuático es pertinente porque los cimientos son así de movedizos desde la llegada del patriarca, don Buenaventura (padre de Quintín, este último esposo de la narradora) a la isla en 1917, quien se arroga que su antepasado es Francisco Pizarro, el conquistador. El párrafo que abre la novela ya nos ubica en el centro verdadero de la casa, que es el agua:

Alamares ocupaba una estrecha lengüeta de tierra, atravesada de extremo a extremo por la avenida Ponce de León, y tenía, como dice, dos caras. Una de ellas, la más pública, daba por el norte al océano Atlántico y a una hermosa playa de arena blanca; la más privada y tranquila daba hacia el sur, hacia la laguna de Alamares, y no tenía playa. Por el lado de la laguna, la avenida colindaba con un enorme manglar, del que sólo se adivinaba el comienzo. En aquel lugar retirado y oculto, donde la laguna moría en el manglar, edificó Buenaventura Mendizábal su cabaña al llegar a Puerto Rico. (21)

Todo el primer capítulo se esmera en describir el emplazamiento geográficoecológico del lugar, su fauna, su flora, los afluentes de los canales, las garzas que como en La vorágine allí habitaban, las leyendas que atravesaban el lugar, y su cuidador:

8 Hay otros secretos ocurriendo en el espacio de la trama: los niños engendrados por el patriarca en las mujeres negras, el tráfico con los alemanes que se piensa es fuente de fortuna, y otros.

9 "Durante los veinte minutos que se tardaba en cruzar la laguna de Marismas, casi no se podía respirar. Del agua fangosa en la que se veía flotar todo tipo de basura, emanaba un hedor insoportable. En un extremo de la laguna se divisaban las casas de Las Minas montadas en zancos, que pronto dejábamos atrás, acelerando el bote hacia la playa de Lucumí. Al rato, las aguas terrosas se aclaraban y, al final del túnel de mangle, se divisaba la marejada blanca del Atlántico bullendo a la distancia. La playa de Lucumí era espléndida, toda de dunas blancas, con centenares de palmeras cimbréandose en el viento" (227). 
Un día el cuidador de la fuente de Alamares amaneció muerto de un golpe misterioso en el cráneo, tendido junto al manantial. (...) Buenaventura Mendizábal se mudó a la casa del cuidador sin que nadie lo objetara. Limpió la fuente de arbustos y la volvió a poner en uso; y desmontó la propiedad circundante de malezas. A aquel modesto bungaló de piedra se fue a vivir Rebeca Arrigoitia después de su boda con Buenaventura, sin que echara de menos para nada la lujosa mansión de sus padres, de tan enamorada que estaba de su marido por aquel entonces. La muerte del cuidador fue un golpe de suerte para el extremeño. (23, mis énfasis)

Advertimos la descripción detallada del lugar y lo enigmático de los gemidos que emanan del mangle para luego aludir a la muerte del cuidador de nombre desconocido que abre la novela justo después que se presenta a Buenaventura mudándose cerca del manantial/fuente de piedra que el otro cuida y mantiene despejada "porque se consideraba propiedad pública". ${ }^{10}$ Sin embargo, aquí lo que importa es el acecho, que concluye con ese "golpe de suerte" al que alude la cita. Golpe de suerte o golpe en el cráneo, da lo mismo; la escritura aproxima el hecho y los motivos que rodean ese "azar" con el que comienza la riqueza, el acto violento de fundación. Se dice en la novela que "no había una fuente de agua potable en veinte millas a la redonda" (24) para recalcar que el patriarca trueca esa agua con que se sirven los buques españoles por el vino que le obsequian y que luego vende, hasta finalmente establecer un almacén. También se dice que Buenaventura “introducía ilegalmente casi todos sus productos a la Isla en barcazas de poco calado que recogían la mercancía en la playa de Lucumí” (24) para luego pasar entre los mangles hasta llegar a la laguna de Alamares. En síntesis, la trayectoria ilícita es precedida de otro acto ilícito: el crimen y la apropiación ilegal de un bien público caído en desuso, sustituyendo un cuidador del bien público (el "viejo artrítico" cuidador de la fuente) por un especulador que se lo apropia. Y la conclusión de la novela destaca el acto depredador pues antes de morir el patriarca, que acostumbra bajar a la pileta o fuente para rejuvenecerse en dichas aguas, dice, acosado por la culpa: "Nunca debí edificar mi casa sobre una fuente pública [...]. Edifiqué mi fortuna sobre el agua, y toda el agua que mana de la tierra es gratis porque viene de Dios" (277). El daño entonces no sólo consiste en un posible asesinato y en ocultar la fuente que ahora forma parte

${ }_{10}$ El hecho jurídico es que el surgimiento de las servidumbres en las casas de la ficticia Alamares (hoy Miramar) ponen en desuso dicho manantial y el mangle lo arropa (21), según se relata en la novela. De otro lado, según un caso judicial de 1913, en 1903, la Asociación Cooperativa de Construcciones, Ahorros y Préstamos compra una gran extensión de terreno en el área conocida como Miramar para urbanizarla. Los solares estaban sujetos a estipulaciones a las que accedían los compradores, quienes se obligaban con la asociación en "la responsabilidad de las construcciones y obras de calles, aceras, alcantarillados y cañerías de agua a prorrata del costo de ellas, las cuales serían llevadas a cabo por la expresada compañía, siempre que los adquirentes de los solares situados en una misma calle lo solicitaran o antes sin este requisito si así la compañía lo estimaba oportuno". Glines v. Matta. 
de los cimientos de la casa, sino que el robo consiste en privar a los habitantes del uso que puedan derivar de esa agua.

\section{RACIALIZACIÓN DEL ESPACIO, INDUSTRIALIZACIÓN Y "DISCURSO TÓXICO”}

Rosario Ferré emplaza la acción de sunovela en un espacio de creciente modernización ubicado en la zona capitalina, y la novela es un mapa de urbanismo, racialización y acomodo de la pequeña burguesía urbana. Aledaño al Viejo San Juan, por Miramar y Cangrejos, empiezan a asentarse tanto las clases acomodadas como las pobres a inicios del siglo XX (Quiles Rodríguez). Se trata de una zona de desarrollo desigual y en ciernes, y la novela relata el devenir económico de la cabeza de familia y su descendencia, cifrando el espacio en que emplazan y viven. El espacio habitado radica en un escenario único y en tránsito donde el desplazamiento entre la marisma, la laguna y el mar marca las relaciones familiares en un adentro que se desdobla en términos raciales y de clase. La casa emplaza en zona lacustre o terreno bajo y los cimientos lo atestiguan. De frente, el Océano Atlántico y tras esa fachada, por detrás de la Avenida Ponce de León, todo un escenario lacustre poblado de cangrejos evoca la población negra que habitó esta zona. Es decir, el emplazamiento físico de la casa, lo que un estudioso ha llamado el espacio percibido permite un tráfico secreto de naturaleza racial, sexual, económica y política, ya que allí se genera la rebelión política del descendiente. Todo esto aflora principalmente al finalizar la novela porque antes lo que se historia es el surgimiento del capital de los Buenaventura. Paralelo a la consolidación del capital en manos de este comerciante emprendedor y autosuficiente, se va puntualizando la historia política y económica de Puerto Rico en un contrapunto a dos voces, femenina una y masculina la otra, que recuenta un mismo relato desde la intensidad de la narradora de ficción y la pseudobjetividad del historiador.

La superposición de un paisaje lacustre y clandestino y de otro dictado por la modernización, en donde se pasean los autos Packards Bentleys y Stuz-Bear Cats (22), produce un violento vaivén entre el suburbio de Alamares con vista al Atlántico y los caños que descubren la marisma a partir de la coyuntural avenida Ponce de León. Entre ese paseo fácilmente recreable mediante las fotos de época y el olor a mangle que depura una lectura que invita a registrar el repertorio olfativo de lo cerrado y de lo abierto, de lo visible y lo invisible, del arriba y el abajo de la casa, discurre la topología de esta casa bachelardiana y marxistoidea a su vez. Quiero detenerme en la lectura topológica del habitáculo y la socioeconomía del lugar que evocan las genealogías de la modernidad a raíz del enclave sociojurídico de los bienes públicos, en particular, el manantial. La flora del manglar y los seres luminiscentes que allí gimen casi son atrapados por los rizomas nudosos que anegan el agua. Según el texto, la Laguna de Marismas se convierte en ciénaga pestilente por el efecto de la contaminación que produce el vertedero del excedente de la Central Oro Miel.

$111 \frac{\text { Revista Iberoamericana, Vol. LXXXII, Núms. 255-256, Abril-Septiembre 2016, } 619-635}{\text { ISSN 0034-9631 (Impreso) }}$ 
La vida amenazada por lo tóxico suscita más conciencia ambiental que el proyecto preservacionista. ${ }^{11} Y$ lo que se representa en este pasaje es un discurso tóxico que soslaya una mirada exotista de la playa y produce una llamada de atención a los procesos de la industrialización y el progreso tecno-económico sin la fantasía escapista sobre la belleza 'natural'. Según Buell, en un nuevo discurso tóxico no apegado a las dicotomías frecuentes, las fronteras del discurso de la naturaleza y el ambiente se desdibujan y se diluyen las oposiciones entre campo/ciudad. En ese sentido, La casa de la laguna enclava en un lugar atravesado por las contradicciones que genera la modernidad en su producción de nuevos paisajes geográficos, pues esta radica en un terreno marcado por la explotación ambiental donde los pobres son segregados y confinados a vivir en las zonas más contaminadas, mientras que ahí mismo se registra la transformación histórica que acarrea una construcción. La casa moderna en medio de la marisma no soporta un habitante único. Todo lo contrario: aquí confluyen la raza negra y la blanca en un mestizaje que ejemplifica el mismo árbol genealógico incluido en la novela. En ese sentido, Ferré ha complicado la faz pretendidamente urbana de la mansión para colocarla en el terreno fronterizo del intercambio racial y cultural del vecino negro que vive dentro. ¿Homenaje velado a José Luis González en El país de los cuatro pisos, quien coloca en sus cimientos a la población negra, o crítica evidente al conocido cuento de René Marqués sobre la demolición de una casa ancestral? La de Ferré no admite fisuras porque lo contiene todo: es una mansión/arrabal, y lo mismo se aspira aire salino desde la terraza que olor a marisma al bajar al sótano. Como señala David T. Goldberg, el espacio perifráctico no requiere lanzar a las periferias físicas a los pobres, les asigna un lugar en la ciudad donde carecen de acceso a bienes y servicios. En esta casa viven en la oscuridad, separados e invisibilizados, confinados a la parte de abajo, privados de apellido, los hijos engendrados con las negras. ${ }^{12}$ Como hemos visto, en lo que respecta sus orígenes, la historia, geografía y atributos físicos de la propiedad permiten hacer un cuestionamiento sobre la legitimidad de la propiedad y el robo y secuestro que se hace del bien público. Y en el presente continuo de la casa, el abuso se perpetúa a través de la estricta racialización del espacio interior de esta, en específico el sótano donde radica la fuente. En el espacio superior habitan las clases adineradas, mientras que en la sombra cercana al mangle se oculta toda la familia de la matrona negra que es criada de la casa, así como la vía que da cauce al comienzo de la insurrección del hijo mayor.

\footnotetext{
11 Respecto al discurso tóxico, véase Buell.

12 "Desde el principio, Santurce fue un asentamiento ambiguo, contradictorio, un espacio negociado producto de la mezcla, la yuxtaposición y el bricolaje de formas de organizar y utilizar el suelo como una frazada de retazos dispares que al encontrarse forman bordes y lugares comunes. Santurce desplegó sobre el territorio una malla de calles, caminos y callejones de múltiples direcciones” (120). Según José Luis González, el primer piso es la cultura afrontillana y el tercero representa la hibridez que combina el espacio impuesto por los españoles y las formas de los barrios rurales cangrejeros.
}

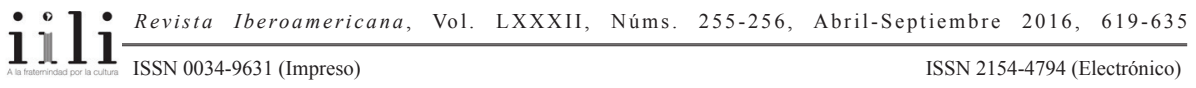


La localización de la casa, pues, parece ubicarse entre uno y otro terreno racializado que deviene arrabal. ${ }^{13}$

\section{LA ‘SELVA ENMARAÑADA’ Y EL DESBROZADOR}

La novela detalla las coordenadas no sólo geográficas, sino de raza y clase, que atraviesa toda la trama. Las coordenadas geopolíticas en términos de la oposición imperio norteamericano/viejo imperio español son mediadas por un proveedor comercial que se beneficia de la drástica desaparición del cañaveral en el mismo lugar donde se abastecerá el capital industrial basado en el intercambio de bienes exportables e importables:

En el siglo XIX, una destilería de ron, la central oro Miel, se había establecido en sus riberas, y vaciaba allí un mosto hediondo que transforma la laguna en una ciénaga. La central azucarera tuvo que cerrar a comienzos del siglo XX, pero las aguas permanecieron contaminadas. Muchos de los acueductos de la ciudad desaguaban en ella; era más económico deshacerse allí de las aguas negras que acarrearlas hasta las playas de arena blanca, las cuales los turistas empezaban a visitar. A orillas de la laguna de Marismas prosperaba el arrabal Las Minas, uno de los lugares más deprimentes de la ciudad. Casi todos los sirvientes que trabajaban en las casas del elegante suburbio de Alamares vivían en aquel lugar y, a menudo, cruzaban en bote el laberinto de los mangles para llegar hasta allí. (23)

De momento, ya hay una opción racializada aquí en términos de dónde verter el desperdicio: en los lugares bajos (cerca del Arrabal Las Minas), con los que el imaginario puebla el habitat de las poblaciones negras, y no en las arenas blancas de las playas destinadas al turismo. La novela se ocupa de describir detalladamente el espacio geográfico discriminatorio que genera esta división de clase y raza justo al principio del texto, evocando lo que hoy correspondería a la zona del Caño Martín Peña. Así como la laguna se convierte en vertedero, así la vieja fuente de agua como bien público se privatiza y en su origen enmalezado se sustituye a su cuidador: un propietario por usucapión a quien nadie le disputa el predio, por ser un comerciante español en ciernes descendiente de Francisco Pizarro, conquistador del Perú. Frente a la "selva enmarañada" (de Hostos cit. en Quiles 112) donde vivían los negros, aparece el propietario blanco y desbrozador:

${ }_{13}$ La noción del caserío o arrabal -slumliness- concepción del espacio del marginado racial. "The slum is by definition filthy, foul smelling, wretched, rancorous, uncultivated, and lacking care. The racial slum is doubly determined, for the metaphorical stigma of a black blotch on the cityscape bears the added connotations of moral degeneracy, natural inferiority, and repulsiveness. It serves as an example of the spatial contradictions identified by Foucault's notion of heterotopia. The slum locates the lower class, the racial slum the underclass" (Goldberg 75).

$111 \frac{\text { Revista Iberoamericana, Vol. LXXXII, Núms. 255-256, Abril-Septiembre 2016, }}{\text { ISSN 0034-9631 (Impreso) }}$ 
Un día, el cuidador de la fuente de Alamares amaneció muerto de un golpe misterioso en el cráneo, tendido junto al manantial. Una pequeña nota apareció en los periódicos pero nadie le puso atención, y el suceso se olvidó pronto. Buenaventura Mendizábal se mudó a la casa del cuidador sin que nadie lo objetara. Limpió la fuente de arbustos y la volvió a poner en uso; y desmontó la propiedad circundante de malezas. A aquel modesto bungaló de piedra se fue a vivir con Rebeca Arrigoitia después de su boda con Buenaventura, sin que echara de menos para nada la lujosa mansión de sus padres, de tan enamorada que estaba de su marido por aquel entonces. (23; énfasis suplido)

Se asume el señorío sobre el lugar que ocupa el manantial de agua aproximadamente en la segunda década del siglo XX. El texto no alude directamente al asesinato, pero lo insinúa y sobre esas bases secretas o insinuadas se descorre el resto de la anécdota que atañe a la escritura de un texto que es la misma novela. Es interesante que este dato principal se revele desde sus inicios porque es la clave de carácter que despojará al descendiente de Buenaventura del menor ápice de humanidad. Un acto delincuente inicia el texto, el del asesinato; posteriormente, se tratará de contrabando. La escasez de agua que consumían los barcos norteamericanos, los españoles la truecan por vinos, jamones y mazapanes mientras Buenaventura se la facilita a través del manantial. Al afinar el contrabando, los buques españoles entraban por la vía ilegal del mangle y la laguna, mientras que los norteamericanos gozaban de los privilegios y el derecho de paso por el Atlántico. Mientras tanto, en la zona urbana de la clase pudiente, a las afueras del centro urbano colonial, se construye el Hotel Astor (¿el Caribe Hilton, el Normandie?), en la playa que da al Atlántico en la ficticia Alamares, y el arquitecto Pavel es asediado por todos los barones del azúcar para que les construya una casa.

De otro lado, en esa misma zona proliferan los barrios populares contaminados de la ciudad industrial. Se trata de los arrabales en la zona de Santurce que responden a los nombres de Cangrejos, Corea, Tokío, El Fanguito, Hoyo Frío, Cantera y Sal si Puedes; en San Juan, los barrios de Culo Prieto, Hoyo Vicioso, Ballajá. Según Edwin Quiles, la ciudad murada y colonial respondía a una retícula militar y a su salida se forman "rancherías" de bohíos y casas de negros (de Hostos cit. en Quiles) y "arrabales intramuros", al estilo de las ciudades musulmanas de la Edad Media (según Fray Iñigo Abad). Cuando el espacio formal se institucionaliza, la ciudad informal se puebla de bohíos. Históricamente, la ubicación de muchos negros libertos provenientes de islas aledañas correspondía al hinterland o periferia de la ciudad formal en el siglo XVII, donde también viven muchos cimarrones que luego son trasladados más allá del Puente San Antonio hacia los terrenos bajos y lagunares de Cangrejos que llegan al Caño Martín Peña. A esto el historiador Adolfo de Hostos le llama "selva enmarañada". Lo rural y lo urbano conviven, pero en el imaginario se le asigna al negro la ruralía y de ahí su territorio enmarañado y enfangado al vivir en tierras bajas y humedales, y la urbanización se le asigna al blanco que va desbrozando las tierras bajas a medida que

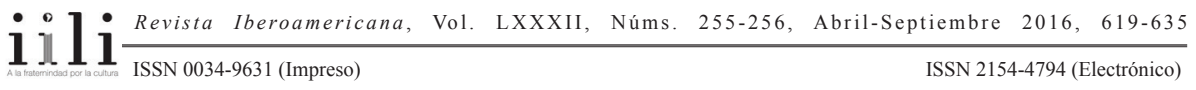


se secan y las ocupa para su beneficio. Y todo ello dividido por la Carretera Central. ${ }^{14}$ Según Quiles, "Desde el principio Santurce fue un asentamiento ambiguo, contradictorio, un espacio negociado producto de la mezcla, la yuxtaposición y el bricolaje de formas de organizar y utilizar el suelo como una frazada de retazos dispares que al encontrarse forman bordes y lugares comunes. Santurce desplegó sobre el territorio una malla de calles, caminos y callejones de múltiples direcciones" (120). Se trata de un territorio cimarrón y marginal que está teñido de implicaciones delictuales que escapan al control social y se invisibilizan por cuestionar el discurso oficial (125). ${ }^{15}$ Por agua llegaba el sustento a San Juan, y el agua también sostuvo a Buenaventura. En ese sentido, señala Quiles: "[e]l agua despertaba la sensación de vulnerabilidad, de estar a merced de lo desconocido. Por eso los bordes de los cuerpos de agua internos se convirtieron en tierra de nadie, lugar disponible para quienes se arriesgaran a ocuparlo" (2-3).

En la novela coexiste el proyecto de modernización de su habitante español, así como la ostentación del progreso, junto con el tráfico racial y erótico a través de las vías navegables sobre las cuales se asienta. Originalmente, la Laguna de San José y la de Torrecillas eran canales que se tornaron navegables para las mercancías desde la bahía de San Juan. Muchos de estos canales servían para transportar la producción de caña de azúcar en Loíza, pueblo de negros. De ahí la importancia del doble emplazamiento estratégico de la mansión y su crecimiento vertical por un lado hacia lo visible y su extensión rizomática horizontal hacia abajo. La superior linda con lo blanco y la inferior con lo negro. Se trata de una especie de palimpsesto donde sucesivas reconstrucciones o remodelaciones dan muestra de su modificación visible, mientras los cimientos permanecen iguales, principalmente preservando el manantial de agua. Como señala José Luis González en El país de cuatro pisos, el español se aprovecha de las rutas del territorio de contrabando del cimarrón para burlar la vigilancia del Estado. En la novela asistimos, por un lado, a la impronta individual, pícara y delictual del dueño de casa vis a vis el espacio comunitario negro, jerarquizando el tejido social en los estamentos

14 "El escenario principal del encuentro fue la Carretera Central, bordeado por una profusa y extensa vegetación de cocoteros, árboles y maleza que hacía parecer impenetrable el mundo más allá, el territorio negro. A partir de este eje se organiza la penetración de los blancos y su dominio eventual del territorio cangrejero. Con la ocupación del camino la vegetación que formaba una tapia de maleza continua fue gradualmente sustituida por construcciones, empalizadas de madera, muros y balcones, señales indiscutibles de la ocupación y el dominio de lo natural" (Quiles 16).

15 "El territorio cimarrón ofrecía las condiciones ideales para el clandestinaje y la actuación al margen de la autoridad. Por sus aguas, además de lanzarse ataques contra la ciudad, floreció el contrabando. Sus márgenes sirvieron también de escondite para otras actividades ilícitas tales como la fabricación de rones" (Quiles 125). Para los extraños que no conocen sus códigos estos lugares adquieren "un carácter tenebroso, ajeno, decadente, que confronta los cánones y elude los controles sociales. Por eso se les teme, se les esconde y se les borra de la memoria histórica, o se representan y reinterpretan de manera que puedan ser apropiados por la oficialidad" (125).

$111 \frac{\text { Revista Iberoamericana, Vol. LXXXII, Núms. 255-256, Abril-Septiembre 2016, }}{\text { ISSN 0034-9631 (Impreso) }}$ 
de la casa. La casa, que es indicio de movilidad social en esta clase media alta, implica también hibridación y mestizaje. Sobre ese Santurce (Cangrejos) donde emplaza la casa, dice Quiles:

Ante la ausencia de guías, Santurce se desarrolló entre la red de caminos y la morfología de las parcelas del barrio cangrejero y las decisiones locales de los terratenientes. En Santurce, la unidad del conjunto y la capacidad de las manzanas de la ciudad tradicional se rompen para dar paso a la ciudad jardín, el suburbio, mezcla de campo y ciudad. (77)

\section{El ENTRAMADO}

La casa de la laguna ocupa varias encrucijadas espaciales y ambientales por razón del lugar donde se ubica, una por razón del manantial secreto que guarda en el solar y otra por la ubicación misma del solar en la zona marítimo-terrestre. Nos remitimos nuevamente a la trama de un caso discutido en el Tribunal Supremo de Puerto Rico en $1995^{16}$ en el que unos vecinos de Lares se disputan el derecho a usar un ojo de agua sito en una finca privada. Invocando los derechos inherentes a la titularidad, el propietario les negaba el derecho a servirse de la servidumbre. Precisamente en este caso se reconoce que el agua en Puerto Rico había sido nacionalizada en virtud de una Ley de 1976 (Ley de Aguas), la cual señala que las aguas superficiales, subterráneas o costaneras son parte del dominio público. Dado que en 1976 se nacionalizan las aguas, también "la política pública del Estado Libre Asociado en torno a este recurso natural" la considera "patrimonio nacional". ${ }^{17}$ En La casa de la laguna el golpe de fortuna del protagonista es esa ocupación de facto que probablemente signa también al anterior ocupante, en virtud de la cual funda su fortuna no sobre una piedra sino sobre el agua

\footnotetext{
${ }^{16}$ Una de las conclusiones del caso señala: "La Ley de Aguas de 1976 fue aprobada por la Legislatura con dos (2) propósitos en mente. El primero, y más importante, era nacionalizar las aguas del País, intención dimanante de la adopción del enfoque integral del ciclo hidrológico. La ley declara como propiedad y riqueza del Pueblo de Puerto Rico, '[t]odas las aguas y cuerpos de agua'de la Isla y le impone al Estado Libre Asociado el ineludible deber de administrar y proteger las aguas de nuestro país, a nombre y en beneficio de la población puertorriqueña. [...] La ley adoptó el principio de la integridad del ciclo hidrológico, por ende la necesidad de incluir dentro del plan de administración todas las aguas y cuerpos de agua. En la exposición de motivos se expresó: 'El propio ciclo hidrológico [...] constituye [...] una unidad, en vez de una sucesión de fenómenos aislados"' (Paoli Méndez v. Rodríguez).

${ }^{17}$ En el caso de la Ley de Desarrollo de Aguas se cita al juez Negrón García cuando señala que la sección 19 del Art. VI de la Constitución del Estado Libre Asociado, LPRA, dispone que "[será política pública del Estado Libre Asociado la más eficaz conservación de sus recursos naturales, así como el mayor desarrollo y aprovechamiento de los mismos para el beneficio general de la comunidad..." (379). A la página 464 añade; "como complemento a la Ley sobre Política Pública Ambiental de 1970 se presenta legislación que sirvió de base a la Ley para la Conservación, el Desarrollo y Uso de los recursos de Agua de Puerto Rico (en adelante Ley de Aguas de 1976).
} 
que posteriormente en el 1976 será reconocida como un bien público. ${ }^{18}$ Es sobre ese bien público que éste se enriquece al condicionar el uso que pueda extraer de un manantial que se halla en zona baja.

Tan recientemente como en el 2005 se debatió otro caso en el Tribunal Supremo y en el país relacionado con el derecho de un constructor para erigir un hotel en la zona marítimo-terrestre en el llamado caso Paseo Caribe, que produjo una Opinión Consultiva del Departamento de Justicia ${ }^{19}$ y eventualmente una decisión controvertida que atañe a terrenos ganados al mar que originalmente pertenecían a la Corona y fueron cedidos (mediante el Tratado de París) a la marina de guerra norteamericana por razón de la posición estratégica que ocupaban. Estas tierras eran consideradas tierras públicas reservadas para usos públicos, pero son arrendadas por 99 años a un general norteamericano de apellido Baker (según permiso del Congreso viabilizado por el Secretario de la Marina) en $1921 .{ }^{20}$ En la opinión consultiva se alude a que estos terrenos eran de dominio público por ser terrenos ganados al mar y que además los cubre la Ley de Puertos de 1880 que señala que pertenecen a la zona marítimo terrestre y por tanto de dominio nacional y uso público. Estos son bienes de dominio público, no son susceptibles de propiedad privada o enajenación, no se pueden gravar y son imprescriptibles. Tenemos aquí otro ejemplo de violaciones sobre el derecho a la propiedad pública, enajenación fraudulenta, rentas del inmueble que equivalen a enajenaciones, apropiación privada del bien público.

En última instancia, se trata de la violencia, del cuestionamiento de una justicia que no aflora, precisamente por razón de la manipulación del derecho. Si bien La casa de la laguna se inicia con una duda de parte de una futura desposada sobre el riesgo de contraer matrimonio con un hombre violento, la violencia viene a manifestarse sutilmente desde sus inicios y no la define necesariamente la muerte del pretendiente

18 En Paoli Méndez, Parte IV del caso, en síntesis, el derecho que adquiere el concesionario a esas aguas es un derecho real condicionado por las disposiciones generales y el concreto título concesional, mientras que el cesionario no tiene la propiedad de las aguas porque siempre serán públicas. Quien tiene potestad para facilitar esas franquicias de aguas es el Secretario de Recursos Naturales, y no es prerrogativa del dueño de la finca donde se hallan las aguas el discernir si concede o no la franquicia.

19 Consulta num 07-130-B emitida por Roberto Sánchez Ramos el 11 de diciembre de 2007.

20 El contrato era fraudulento pero se juzgó válido en 27 F2d 863 (1928, first Circuit) y se llevó a corte en los Estados Unidos. Puerto Rico interviene reclamando los terrenos sumergidos, pero no le da seguimiento. El contrato era nulo pues su objeto eran terrenos sumergidos pertenecientes al gobierno insular por la Ley Jones -todo terreno sumergido, aguas navegables pasan al gobierno de Puerto Rico (página 11 de la opinión). Ver página 14 para observar la desidia de PR para reclamarlos. Estos terrenos aledaños al Coast Guard Parcel fueron transferidos al gobierno de PR en 1940 (Ley 66): transfiere mangles, cuerpos de agua en la bahía, etc. El traspaso no modifica el estatuto de bienes de dominio público. Sucesivamente, son rellenados por la Compañía de Fomento Industrial con propósitos turísticos y Baker cede su interés como arrendador a la compañía gubernamental de Fomento Industrial. Posteriormente, esos terrenos son vendidos al Caribe Hilton en el 1998 y son cedidos por el ELA a la compañía de turismo que los vende al Hilton.

$111 \frac{\text { Revista Iberoamericana, Vol. LXXXII, Núms. 255-256, Abril-Septiembre 2016, }}{\text { ISSN 0034-9631 (Impreso) }}$ 
anterior dado el trato cruel del prometido actual, sino el desplazamiento paulatino de una clase agrícola por una industrial alegorizada en la casa y en las transformaciones que allí se operan, todas ellas transformaciones cosméticas que no dan fe de los cimientos tenebrosos de su primer habitante. Aquí radica la ambigüedad de la obra, porque los habitantes de las sombras, o los negros, son investidos, a su pesar, de un elemento opaco y secreto. La casa bachelardiana tiene esas dos fugas en su lectura vertical, la del ático y la del sótano. Así también, en la estructura de El país de cuatro pisos de José Luis González, los negros constituyen el primer escalafón o fundamento, blanqueado posteriormente por las capas sucesivas de una población emigrante. Españoles, italianos y corsos ocupan las estancias superiores en la casa y en el árbol genealógico, mientras que a la izquierda de ese mismo árbol se hallan Petra, Carmelina, Alwilda y Carmelina Aviles, la bebé negra. Valga destacar que en cuanto en ese lado izquierdo del árbol se trata de mujeres sin cónyuge, los hijos blancos abusan de las negras y la madre soltera emigra a Nueva York. ${ }^{21}$

No olvidemos que aquí todo gira en torno a una casa escindida en dos. Y que toda la política, principalmente la que incide en lo económico, discurre entre los diálogos. Como el progreso es medido en términos de las transformaciones de la casa, es en la casa/arrabal que se genera la rebelión contra el padre, así como la subversión feminista. La casa está ahí para destruirse, cuestionarse, demolerse. La violencia que funda la progenie está para cuestionarse. Y conjuntamente con la violencia, la injusticia social. Ya la casa es el producto de la injusticia ambiental pues confina a los negros a vivir en los cimientos del mangle. Según Harvey, el capitalismo produce unas ciertas geografías que se alteran en la medida de sus necesidades, de modo que el paisaje urbano va cambiando, destruyéndose y reconstruyéndose a su vez. Y añade Soja, que la ciudad industrial capitalista es una máquina generadora de desigualdades así como generadora de crisis. A la par que se construyen las capitales, también van decayendo los ghettos, los centros de la ciudad, y se crea el desparramamiento urbano, la fragmentación, la inadecuación de los servicios públicos (89). La novela muestra casi un espacio interior, y subrayo el casi, porque la construcción y remodelación de esta casa se inserta en el tiempo del industrial que la maneja, pasando a segundo plano la disputa entre la mirada del historiador patriarcal y la visión de la ficción feminista. Es decir, leída la novela en el contexto de nuestra literatura puertorriqueña, de nuestras relaciones sociales, y la producción paulatina de un espacio urbano, esta casa ocupa un lugar especial en ese San Juan con sus suburbios que Magali García Ramis, José Luis González, René Marqués, Josué Montijo, Marta Aponte Alsina, Myrna Báez, Edgardo Rodríguez Juliá y Eduardo Lalo han querido cuestionar. El texto que se produce aquí es el de una casa que se autodestruye por razón de las disputas relativas a la representación y sobre todo porque los dos énfasis, el de

${ }^{21}$ Remitimos a la página 11 del texto: "Árbol familiar”.

$111 \frac{\text { Revista Iberoamericana, Vol. LXXXII, Núms. 255-256, Abril-Septiembre 2016, 619-635 }}{\text { ISSN 0034-9631 (Impreso) }}$ 
la raza y el de la política, han sido subestimados y ocultados en el sótano. Es por estar allí, en el piso más bajo de la casa, que logran subvertir precisamente los cimientos. Si por un lado el narrador de René Marqués en "Ese mosaico fresco sobre aquel mosaico antiguo" deviene testigo de la demolición de una casa construída por el famoso arquitecto Nechodoma (alias Pavel, en la novela de Ferré), la narradora de Ferré la reconstruye dando fe de sus cimientos. Al reconstruir la historia y el emplazamiento fictivo de la casa de esta laguna la autora realmente la está demoliendo, descubriendo la injusticia social en la base de sus cimientos, reconstruyendo su genealogía, y en ese sentido llevando a cabo un proyecto inverso al de Marqués, quien tan sólo lamenta nostálgicamente la destrucción de un mundo en la casa Georgetti. Como señala Blomley, el espacio también es producido en el sentido de mirarlo o aprehenderlo como paisaje representado por el poder. El modo en que la crítica literaria se posiciona ante ese espacio conforma una ideología visual. En esta novela, paradójicamente se presenta la historia de una clase comercial en pleno desarrollismo que marcha paralela a su ficcionalización. Pero, sobre todo, se describe la casa que la signa en una ciudad racializada y discriminada, y el principio violento que la funda: la apropiación de un bien público. La borradura de los otros (negros, mujeres y pobres) y el asesinato inicial son revertidos al hacer justicia con el incendio de la casa.

\section{BibLIOGRAFÍA}

Bachelard, Gaston. La poética del espacio. 1957. Ernestina de Champourcin, trad. México: Fondo de Cultura Económica, 1965.

Blomley, N. K. Law, Space, and the Geographies of Power. Nueva York: Guilford Press, 1994.

Buell, Lawrence. “Toxic Discourse”. Critical Inquiry 24/3 (1998): 639-665.

Constitución del Estado Libre Asociado. San Juan: LPRA, 1922. Vol. 1

Consulta núm. 07-130-B, emitida por Roberto Sánchez Ramos, 11 de diciembre de 2007.

Ferré, Rosario. La casa de la laguna. Nueva York: Vintage español, 1996.

Papeles de Pandora. México: Joaquín Mortiz, 1976.

Fontánez Torres, Érika. "The Contingency of Property Policies: A Review of the Assumptions Related to the Political Theory of Property in the Contexts of

Social and Environmental Justice in Puerto Rico." < http://www.law.yale.edu/ intellectuallife/8593.htm>. 13 julio 2015.

Derecho y Propiedad. Buenos Aires: Editorial Libraria, 2008.

Gallart, Mary Frances. "Ahora seremos felices: modelos de urbanización en San Juan".

San Juan siempre nuevo: arquitectura y modernización en el siglo XX. San Juan: AACUPR, 2000. 30-73.

García Ramis, Magali. "Memoria de la ciudad". San Juan siempre nuevo, arquitectura y modernización en el siglo XX. Enrique Vivoni-Farage, ed. San Juan: Archivo de

$111 \frac{\text { Revista Iberoamericana, Vol. LXXXII, Núms. 255-256, Abril-Septiembre 2016, } 619-635}{\text { ISSN 0034-9631 (Impreso) }}$ 
Arquitectura y Construcción de la Universidad de Puerto Rico (ACCUPR), 2000. 10-29.

González, José Luis. El país de cuatro pisos. Río Piedras: Huracán, 1980.

Goldberg, David T. "Polluting the Body Politics: Race and Urban Location." The Legal Geographies Reader. Law, Power, and Space. N. Blomley, D. Delaney y R. Ford, eds. Malden: Wiley-Blackwell, 2001. 69-86.

Glines v. Matta. 19 Decisiones de Puerto Rico (Tribunal Supremo) 409 (1913).

Harvey, David. Justice, Nature and the Geography of Difference. Cambridge: Blackwell, 1996.

Iglesia, Rafael E. J. "Identidad cultural y arquitectura: orientándose en el laberinto". Arquitectura y vida en Puerto Rico (1900-1950). Enrique Vivoni Farage y Silvia Álvarez Curbelo, eds. San Juan: Editorial de la Universidad de Puerto Rico, 1998. $1-23$.

Lefebvre, Henri. The Production of Space. 1974. Donald Nicholson Smith, trad. Oxford: Blackwell, 1991.

Marqués, René. Ese mosaico fresco sobre aquel mosaico antiguo. Río Piedras: Cultural, 1975.

Nechodoma, Antonin. “Arquitectura y arquitectos de Puerto Rico". El libro de Puerto Rico. E. Fernández García, ed. Nueva York: Press of the Lent and Graff Co, 1923.

Negrón García, L. Proyecto de Ley de Desarrollo de Aguas de Puerto Rico. Río Piedras: Ed. Revista Jurídica U.P.R., 1973. 1516.

Nietzsche, Friedrich. La genealogía de la moral. Andrés Sánchez Pascual, trad. Madrid: Alianza Editorial, 1988.

Paoli Méndez v. Rodríguez et al, 138 Decisiones de Puerto Rico (Tribunal Supremo) 449 (1995).

Quiles Rodríguez, Edwin. San Juan tras la fachada. Una mirada desde sus espacios ocultos (1508-1900). San Juan: Editorial del Instituto de Cultura Puertorriqueña, 2003.

Rivera, José Eustasio. La vorágine. Montserrat Ordóñez, ed. Madrid: Cátedra (Letras hispánicas), 2006.

Sepúlveda, Aníbal. Historia ilustrada de su desarrollo urbano, 1508-1898. San Juan: Carimar, 1989.

Soja, Edward. Seeking Spatial Justice. Minneapolis: U of Minnesota P, 2010.

Vivoni-Farage, Enrique, ed. San Juan siempre nuevo: arquitectura y modernización en el siglo XX. San Juan: Archivo de Arquitectura y Construcción de la Universidad de Puerto Rico (ACCUPR), 2000.

y Sylvia Álvarez Curbelo. Hispanofilia. Arquitectura y vida en Puerto Rico, 1900-1950. San Juan: Editorial de la Universidad de Puerto Rico, 1998.

White, Hayden. Tropics of Discourse. Essays in Cultural Criticism. 1978. Baltimore: Johns Hopkins UP, 1990.

$111 \frac{\text { Revista Iberoamericana, Vol. LXXXII, Núms. 255-256, Abril-Septiembre 2016, 619-635 }}{\text { ISSN 2154-4794 (Electrónico) }}$ 
